University of Nebraska - Lincoln

DigitalCommons@University of Nebraska - Lincoln

$10-2006$

\title{
Modeling and Simulation of the Interaction Between Lubricant Droplets on the Slider Surface and Air Flow Within the Head/Disk Interface of Disk Drives
}

Lin Wu

University of Nebraska-Lincoln

Follow this and additional works at: https://digitalcommons.unl.edu/mechengfacpub

Part of the Mechanical Engineering Commons

Wu, Lin, "Modeling and Simulation of the Interaction Between Lubricant Droplets on the Slider Surface and Air Flow Within the Head/Disk Interface of Disk Drives" (2006). Mechanical \& Materials Engineering Faculty Publications. 18.

https://digitalcommons.unl.edu/mechengfacpub/18

This Article is brought to you for free and open access by the Mechanical \& Materials Engineering, Department of at DigitalCommons@University of Nebraska - Lincoln. It has been accepted for inclusion in Mechanical \& Materials Engineering Faculty Publications by an authorized administrator of DigitalCommons@University of Nebraska Lincoln. 


\title{
Modeling and Simulation of the Interaction Between Lubricant Droplets on the Slider Surface and Air Flow Within the Head/Disk Interface of Disk Drives
}

\author{
Lin $\mathrm{Wu}$ \\ Mechanical Engineering Department, University of Nebraska-Lincoln, Lincoln, NE 68588-0656 USA
}

\begin{abstract}
The dynamic interaction phenomenon between three-dimensional (3-D) lubricant droplets located on the air bearing surface and air flow within the head-disk interface is modeled and numerically simulated. A strong interaction is observed for ultra low flying slider design. The droplet motion and deformation are able to induce non-negligible air bearing force and moment change, which in turn may impose a non-negligible disturbance on the slider's flying attitude.
\end{abstract}

Index Terms-Air bearing, disk drives, head/disk interface, interaction, lubricant flow.

\section{INTRODUCTION}

I $\mathrm{T}$ IS estimated that the flying height of air bearing sliders has to be reduced to about $3.5 \mathrm{~nm}$ to further increase the areal storage density of disk drive to $1 \mathrm{Tbits} / \mathrm{in}^{2}$. At such a small clearance, which is approaching the thickness of the lubricant layer coated on the disk surface (about $1.5 \mathrm{~nm}$ ), the interaction between the air flow and lubricant flow may become non-negligible and has to be considered in the designing of next generation head/disk interface technology. Previous researches have demonstrated that the air flow and lubricant flow under the slider are coupled together and the interaction imposes a non-negligible impact on the flyability of low-flying sliders [1]-[5]. In addition, the industry also needs a model that can quantitatively predict the distribution of lubricant contaminations on the slider surface.

Our previous simulations based on a simplified two-dimensional (2-D) model show that a lubricant droplet introduced onto the slider surface may interact strongly with the air flow and trigger significant air bearing force and moment change for low flying sliders [6]. In this paper, we extend the 2-D model to a three-dimensional (3-D) model. A new governing equation is derived for the lubricant flow on the air bearing surface, which includes important physics such as viscous force, air bearing pressure, air shearing force, surface tension and disjoining pressure. Again, a very strong coupling between the lubricant droplet motion and air flow is discovered for ultra low flying slider design. The lubricant droplet is driven to migrate towards the slider's trailing edge predominantly by the air shearing stress. Other effects such as air bearing pressure gradient and disjoining pressure gradient play a secondary role. The droplet simultaneously undergoes significant shape deformation. The moving and deforming droplet in turn modifies the effective air bearing surface profile and induces a corresponding air flow adjustment. Our results based on the new 3-D droplet model show that the lubricant droplet and air flow interaction may induce a non-negligible air bearing force, pitch moment

Digital Object Identifier 10.1109/TMAG.2006.880471

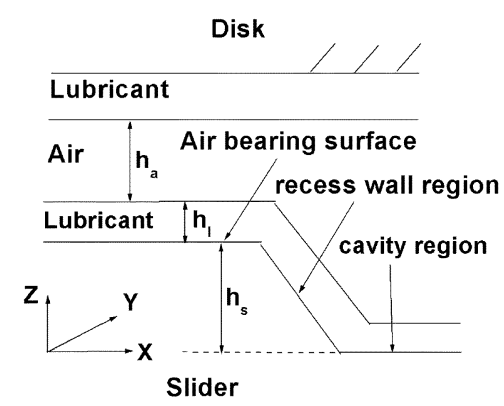

Fig. 1. Diagram of head/disk interface setup.

and slider's flying attitude change for low-flying slider design. Our model is also able to quantitatively predict lubricant contamination distribution on the slider surface.

\section{Governing EQuations AND Numerical Methods}

\section{A. Lubricant Film Thickness Evolution Equation}

Under lubrication condition, the mass balance equation for the lubricant flow is

$$
\frac{\partial h_{l}}{\partial t}+\frac{\partial q_{x}}{\partial x}+\frac{\partial q_{y}}{\partial y}=0
$$

where $t$ is time, $x$ and $y$ are the horizontal coordinates, and $h_{l}$ is the lubricant film thickness (see Fig. 1). The volume flow rates of lubricant per unit length in $x$ and $y$ directions are

$$
\begin{aligned}
& q_{x}=\int_{0}^{h_{l}} u d z=-\frac{1}{3 \mu_{l}} \frac{\partial p_{l}}{\partial x} h_{l}^{3}+\frac{\tau_{x}}{2 \mu_{l}} h_{l}^{2}, \\
& q_{y}=\int_{0}^{h_{l}} v d z=-\frac{1}{3 \mu_{l}} \frac{\partial p_{l}}{\partial y} h_{l}^{3}+\frac{\tau_{y}}{2 \mu_{l}} h_{l}^{2}
\end{aligned}
$$

where $u$ and $v$ are lubricant velocities in $x$ and $y$ directions, $\mu_{l}$ is the lubricant viscosity, $\tau_{x}$ and $\tau_{y}$ are the air shearing stresses in $x$ and $y$ directions, respectively. The pressure within the lubricant film can be obtained through a normal stress balance at the interface to yield

$$
p_{l}=p_{a}-\frac{A}{h_{l}^{3}}-\sigma\left[\frac{\partial^{2}\left(h_{l}+h_{s}\right)}{\partial x^{2}}+\frac{\partial^{2}\left(h_{l}+h_{s}\right)}{\partial y^{2}}\right]
$$


where $p_{a}$ is the air bearing pressure, $A$ is the modified Hamaker constant, $\sigma$ is the surface tension of lubricant and $h_{s}$ is the vertical elevation of the air bearing surface from the fully recessed cavity region, respectively. The meniscus curvature induced capillary pressure term in (3) has two contributions: One directly comes from the change of film thickness $h_{l}(x, y)$, the other from the air bearing surface topography change $h_{s}(x, y)$. Substituting (2) and (3) into (1) and normalizing it, we obtain the dimensionless evolution equation for the lubricant droplet profile

$$
\begin{array}{r}
\frac{\partial\left(H_{l}\right)}{\partial T}+\frac{\partial}{\partial X}\left[\begin{array}{c}
\tau_{x}^{*} H_{l}^{2}-C_{p} \frac{\partial P}{\partial X} H_{l}^{3}-C_{d} \frac{1}{H_{l}} \frac{\partial H_{l}}{\partial X} \\
+C_{\sigma} H_{l}^{3} \frac{\partial^{3}\left(H_{l}+H_{s}\right)}{\partial X^{3}}
\end{array}\right] \\
+\frac{\partial}{\partial Y}\left[\begin{array}{c}
\tau_{y}^{*} H_{l}^{2}-C_{p} \frac{\partial P}{\partial Y} H_{l}^{3}-C_{d} \frac{1}{H_{l}} \frac{\partial H_{l}}{\partial Y} \\
+C_{\sigma} H_{l}^{3} \frac{\partial^{3}\left(H_{l}+H_{s}\right)}{\partial Y^{3}}
\end{array}\right]=0
\end{array}
$$

where $T=2 t \mu_{l} L /\left(\mu_{a} U\right), X=x / L, Y=y / L, H_{l}=$ $h_{l} / h_{f}, H_{s}=h_{s} / h_{f}, P=p_{a} / p_{0}$, and $\tau_{x}^{*}=\tau_{x} h_{f} /\left(\mu_{a} U\right)$, $\tau_{y}^{*}=\tau_{y} h_{f} /\left(\mu_{a} U\right)$ are the dimensionless time, tangential coordinates, lubricant thickness, height of air bearing surface, air bearing pressure and air shearing stresses in the $x$ and $y$ directions, respectively. The disk's linear velocity in $x$ direction, slider's length, flying height, air viscocity and ambient air pressure are denoted $U, L, h_{f}, \mu_{a}$ and $p_{0}$, respectively. The dimensionless groups $C_{p}=2 p_{0} h_{f}^{2} /\left(3 \mu_{a} L U\right), C_{d}=2 A /\left(\mu_{a} L U h_{f}\right)$ and $C_{\sigma}=2 \sigma h_{f}^{3} /\left(\mu_{a} L^{3} U\right)$ represent the ratios of air bearing pressure, disjoining pressure and capillary pressure to the air shearing stress, respectively.

The material parameters for the perfluoropolyalkylether (PFPE) lubricant are: $\mu_{l}=0.1448 \mathrm{~Pa} \cdot \mathrm{s}, \sigma=0.02 \mathrm{~N} / \mathrm{m}$ and $A=10^{-21} J$. For a typical slider design flying at a $10 \mathrm{~nm}$ height ( $L \sim 1 \mathrm{~mm}, U \sim 10 \mathrm{~m} / \mathrm{s}$ ), the order of magnitudes of the dimensionless parameters in (4) are: $C_{p} \propto 10^{-5}, C_{d} \propto 10^{-5}$, and $C_{\sigma} \propto 10^{-13}$.

The extremely small values of $C_{p}, C_{d}$ and $C_{\sigma}$ from dimensional analysis show that the air bearing pressure, disjoining pressure and capillary pressure have a much smaller effect on driving the lubricant flow compared with the air shearing stress. The air pressure and disjoining pressure terms are included in our simulations. The capillary pressure terms are ignored in the following simulation.

\section{B. Numerical Methods}

At each moment, the steady state modified Reynolds equation is solved by a finite volume method using the known lubricant droplet profile. Because the viscosity of air is several orders smaller than that of the lubricant, it is reasonable to assume that the air flow adjusts itself instantly in response to the lubricant droplet profile change. The resulting air bearing pressure is employed to calculate the air shearing stresses from the first-order slip model velocity profiles [6]. Equation (4) is then numerically solved by an implicit hybrid finite difference method [7]. The time marching continues until a targeted time is reached.

\section{RESULTS AND DISCUSSION}

In the following discussion, we assume that the initial shape of each lubricant droplet is described by a spherical cap. We

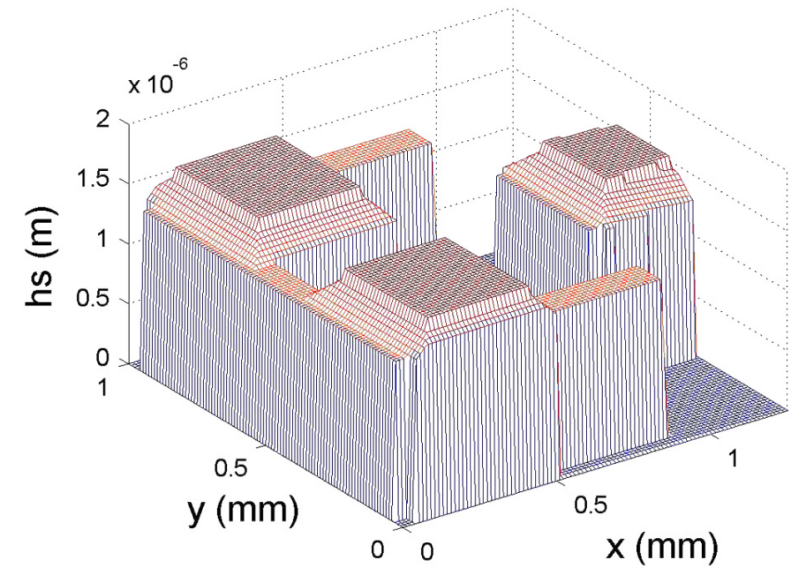

Fig. 2. Geometry of a modified IBM Travelstar slider design. (Color version available online at http://ieeexplore.ieee.org.)

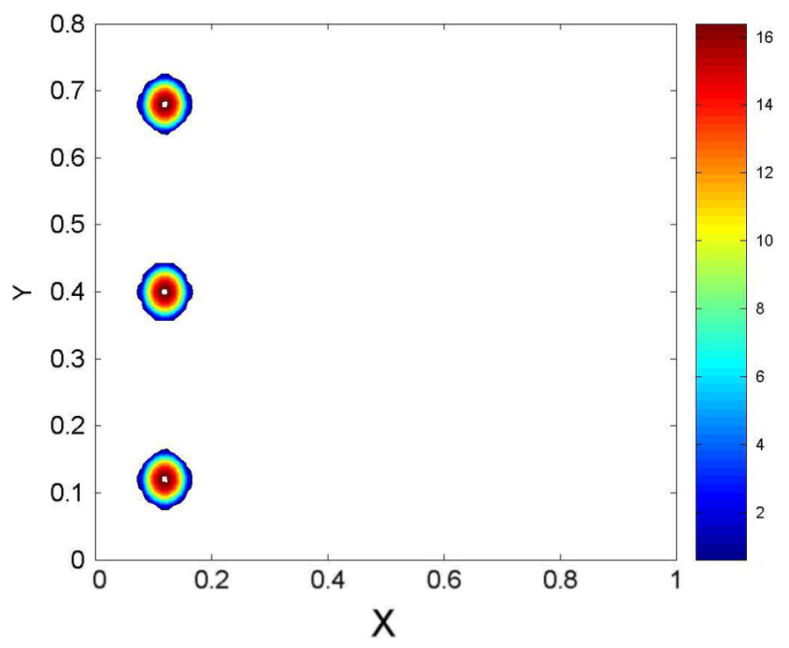

Fig. 3. Initial dimensionless profile of droplets on the slider surface. The droplets have a height of $60 \mathrm{~nm}$. (Color version available online at http://ieeexplore.ieee.org.)

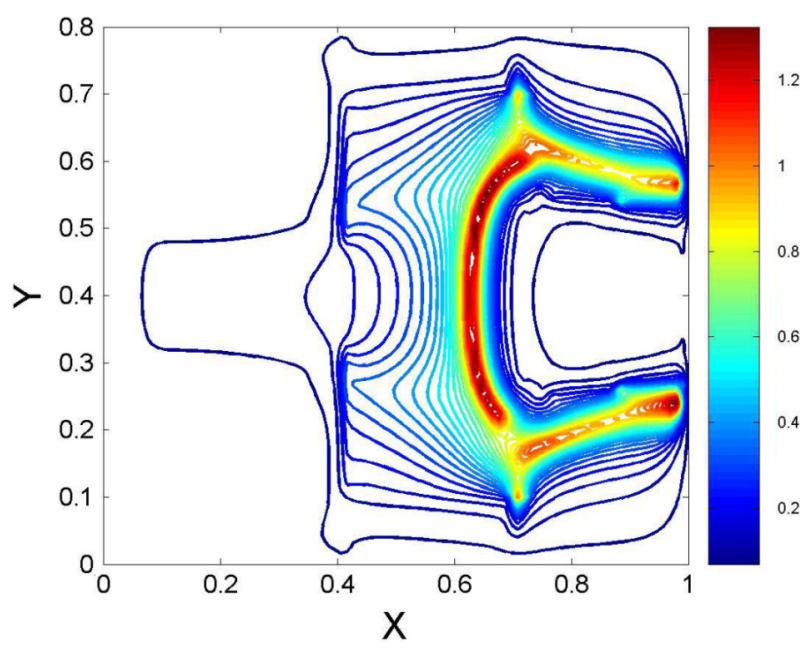

Fig. 4. Contour of lubricant distribution on the slider surface after a sliding of 800 s. (Color version available online at http://ieeexplore.ieee.org.)

use a modified IBM Travelstar slider to illustrate the interaction mechanism (see Fig. 2). The slider is flied at a fixed attitude $\left(h_{f}=3.5 \mathrm{~nm}\right.$, pitch $=100 \mu \mathrm{rad}$, roll $\left.=0\right)$. Three droplets are 


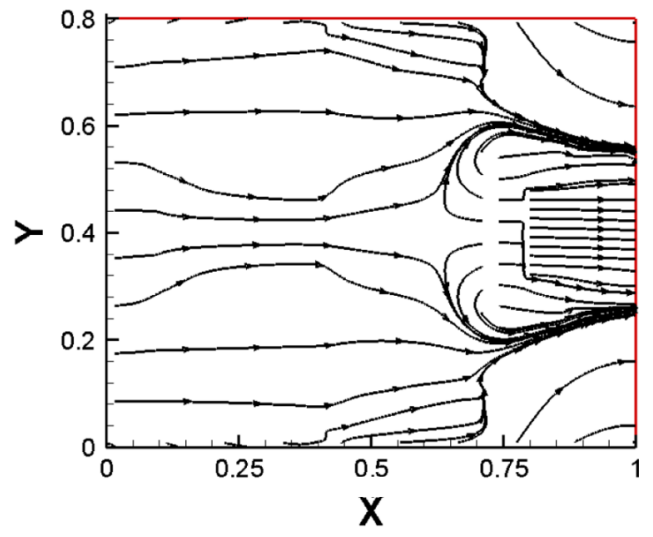

Fig. 5. Skin friction lines of air shearing stress on the slider surface. (Color version available online at http://ieeexplore.ieee.org.)

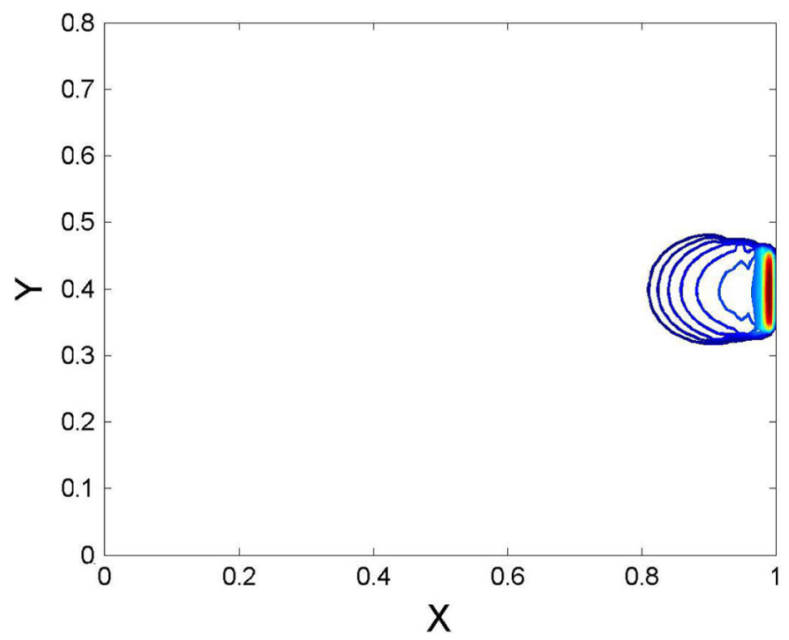

Fig. 6. Contour of a lubricant droplet after $10 \mathrm{~s}$ sliding. The droplet is initially located $(1.1,0.5 \mathrm{~mm}$ ) with a height of $10 \mathrm{~nm}$ and a radius $0.1 \mathrm{~mm}$. (Color version available online at http://ieeexplore.ieee.org.)

initially placed near the leading edge of the slider (see Fig. 3). Fig. 4 shows that the droplets are removed quickly from the air bearing surface by the strong air shearing and are driven into the fully recess cavity region. In the cavity region, the droplets meet to form a lubricant ridge circumscribing the trailing pad and the majority of lubricant is drained toward the two spots on the trailing edge along the two branches of the ridge. The ridge is separated from the trailing pad at the leading edge and its two branches gradually converge to the side walls of the trailing pad. Fig. 5 plots the skin friction lines of the air shearing stress at the slider surface. Figs. 4 and 5 show that the lubricant evolution pattern on the slider surface is predominantly driven by the air shearing stress pattern. The lubricant ridge is formed at places where skin friction lines converge. Fig. 5 also indicates the existence of a reverse air flow region in front of the trailing pad close to the slider surface, which is induced by the pressure gradient there. Our simulation shows a few percent change in the air bearing force during the simulated time period.

Fig. 6 plots the contour of a droplet after a sliding duration of $10 \mathrm{~s}$. The droplet is introduced at the trailing pad before sliding. The majority of lubricant flows to the trailing edge

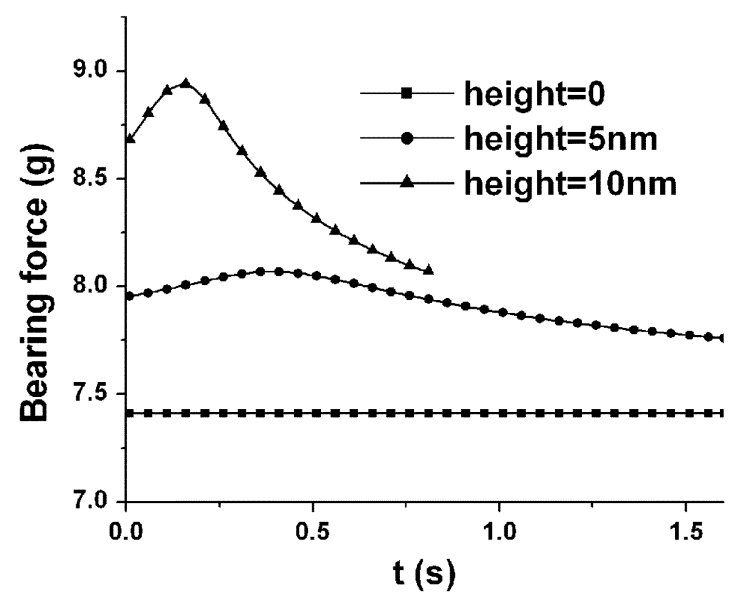

Fig. 7. Air bearing force evolution as a function of the initial droplet height.

quickly driven by the strong air shearing at the pad surface. Fig. 7 plots the evolution history of the air bearing force. Fig. 7 shows that the air bearing force initially increases with time and reaches a maximum value. Then it decreases and approaches the air bearing force without any lubricant on the pad surface. The interaction strength increases with the size of the droplet. Fig. 7 shows that the interaction becomes stronger when droplets are introduced at the trailing pad than at other place.

\section{CONCLUSION}

A new flow model is developed for the interaction phenomenon between droplets located on the air bearing surface and the air flow within the head disk interface of disk drives. Our simulation indicates that the interaction between the droplets motion and the air flow may become strong enough to induce non-negligible air bearing force and moments change when the lubricant droplets are driving to migrate towards the trailing edge of the slider. The interaction phenomenon has to be considered in the designing of next generation head/disk interface technology with an ultra low flying head. The new model is able to quantitatively predict lubricant contamination distribution on the slider surface.

\section{REFERENCES}

[1] S. K. Deoras and F. K. Talke, "Slider-lubricant interactions for low flying sliders," IEEE Trans. Magn, vol. 39, no. 5, pp. 2471-2473, Sep. 2003.

[2] X. D. Ma, D. Kuo, J. P. Chen, H. Tang, and J. Gui, "Effect of lubricant on flyability and read-write performance in the ultra-low flying regime," ASME J. Tribol., vol. 124, pp. 259-265, 2002.

[3] R. Pit, Q. H. Zeng, Q. Dai, and B. Marchon, "Experimental study of lubricant-slider interactions," IEEE Trans. Magn., vol. 39, no. 2, pp. 740-742, Mar. 2003.

[4] X. D. Ma, H. Tang, M. Stirniman, and J. Gui, "Lubricant thickness modulation induced by head-disk dynamic interactions," IEEE Trans. Magn., vol. 38, no. 1, pp. 112-117, Jan. 2002.

[5] D. Qing, F. Hendriks, and B. Marchon, "Modeling the washboard effect at the head/disk interface," J. Appl. Phys., vol. 96, pp. 696-703, 2004

[6] L. Wu, "A 2-D Model for the Interaction between lubricant droplet on the slider surface and air flow within the head/disk interface of disk drives," J. Appl. Phys., vol. 99, 2006. 08N101.

[7] S. V. Patankar, Numerical Heat Transfer and Fluid Flow. New York: McGraw-Hill, 1980.

Manuscript received March 13, 2006 (e-mail: linwu@unlserve.unl.edu). 